\title{
A Biological Perspective on Differences and Similarities between Burnout and Depression
}

Ariane Orosz ${ }^{a, b,}{ }^{*}$, Andrea Federspiel $^{b}$, Sarie Haisch ${ }^{a}$, Christian Seeher $^{a}$, Thomas Dierks ${ }^{b}$, Katja Cattapan ${ }^{\mathrm{a}, \mathrm{b}}$

${ }^{a}$ Sanatorium Kilchberg, Privatklinik für Psychiatrie und Psychotherapie, Kilchberg, Switzerland

${ }^{b}$ University Hospital of Psychiatry and Psychotherapy, Translational Research Center, Bern, Switzerland

Affiliation addresses:

a) Sanatorium Kilchberg AG, Privatklinik für Psychiatrie und Psychotherapie, Centre for Stress Related Illnesses, Alte Landstrasse 70, 8802 Kilchberg, Switzerland

b) University Hospital of Psychiatry and Psychotherapy, Translational Research Center, Bolligenstrasse 111, 3000 Bern 60, Switzerland

\section{Authors' email:}

1) Ariane Orosz, Dr. sc. ETH ${ }^{a, b, *}$

ariane.orosz@sanatorium-kilchberg.ch; orosz@puk.unibe.ch

2) Andrea Federspiel, Prof. Dr. phil. nat. ${ }^{b}$

federspiel@puk.unibe.ch

3) Sarie Haisch, Dr. med. ${ }^{a}$

sarie.haisch@sanatorium-kilchberg.ch

4) Christian Seeher, med. pract. $^{a}$

christian.seeher@sanatorium-kilchberg.ch

5) Thomas Dierks, Prof. Dr. med. ${ }^{b}$

dierks@puk.unibe.ch

6) Katja Cattapan, Prof. Dr. med. ${ }^{a, b}$

katja.cattapan@sanatorium-kilchberg.ch

*Correspondence:

Ariane Orosz, Dr. sc. ETH

Zentrum für stressbedingte Erkrankungen

Sanatorium Kilchberg AG

Alte Landstrasse 70

$\mathrm{CH}-8802$ Kilchberg

Phone: +4144716 4247

Fax: +41447164013

ariane.orosz@sanatorium-kilchberg.ch

Conflicts of Interest: none

Source of funding: none 


\section{Abstract}

To compare and contrast burnout and depression is not only a conceptual issue, but may deliver important directions for treatment approaches and stabilize the awareness of disease which is essential for affected individuals. Because of the symptomatic overlap, it is a subject of multidimensional research and discussion to find specific signatures to differentiate between the two phenomena or to present evidence that they are different aspects of the same disorder. Both pathologies are regarded as stress-related disorders. Therefore, in this review burnout and depression are discussed on the basis of biological parameters, mainly heart rate variability (HRV) and brain-derived neurotrophic factor (BDNF), which are crucial to the stress response system. It emerges that instead of finding one specific discriminating marker, future research should rather concentrate on elaborating indices for burnout and depression which integrate combinations of parameters found in genetics, neurobiology, physiology and environment.

\section{Keywords:}

- Stress

- $\quad$ Stress-related disorders

- Burnout

- Depression

- Autonomic nervous system

- parasympathicus

- Heart rate variability

- Brain-derived neurotrophic factor

- Hippocampal volume

- Childhood adversity

- Allostatic load index 


\section{Introduction}

Finding a designation that describes and explains somatic and emotional suffering is essential for an individual's self-esteem stability (Hillert and Marwitz, 2008). This desire may be a driving force in search for specific markers that might differentiate the similar but still not same phenomena depression and burnout.

The burnout syndrome was originated by the American psychoanalyst Herbert Freudenberger. In 1974, he described the phenomenon that occurred to the "dedicated and committed" usually one year after they had begun working in care-giving occupations (Freudenberger, 1974). Soon, the concept of burnout has been applied to a variety of other professions. To date, neither a concrete scientific description, nor a code in the classification systems (DSM-IV, ICD-10) exist. However, there are three symptoms which are commonly accepted as the core dimensions of burnout, namely exhaustion, depersonalization (cognitive distance toward job by a cynical attitude) and reduced professional efficacy (Maslach et al., 2001) which are a prolonged reaction to chronic interpersonal and emotional stress at work (Maslach and Goldberg, 1998). There is an extended concept that describes the burnout syndrome as a process of increasing exhaustion paralleled by decreasing mental and physical efficiency, caused by chronic stressors in the context of performance in general, which are progressively perceived as non- manageable (Ballweg et al., 2013). Thus, the etiology of burnout is generally thought to be long-term stress. Today, stress is seen in connection with highly demanding and exhausting psychological or emotional situations at work or in social relationships. Irrespective of its character (physical, physiological, emotional, social etc.), the response to stressors follows a common translational physiologic pathway, ending up a dysregulation of homeostatic systems such as the hypothalamus-pituitary-adrenal gland (HPA) -axis (McEwen, 1998). There is broad range of chronic stress-related disorders including migraine, essential hypertension, irritable bowel syndrome, chronic fatigue, fibromyalgia or neurasthenia (Eggers, 2007; Grassini and Nordin, 2015). Chronic stress is also considered as one of the most potent non-genomic factors in the development of mood disorders (Gold and Chrousos, 2002). Also major depressive disorder (MDD) is 
generally considered a stress-related disorder (Bouma et al., 2011; Kessler, 1997; Tennant, 2002). In contrast to the burnout syndrome, MDD is a classified mental disorder (American Psychiatric Association, 2000), and with an estimated life-time risk of at least $10 \%$ one of the most common psychiatric illnesses (Kessler et al., 2003; Weissman et al., 1996). Its characteristics are depressed mood, anhedonia, feelings of hopelessness and guilt, various physical symptoms and an inability to work (American Psychiatric Association, 2000; Meier, 1984). To date depressive disorders - resulting from job stress - become a major cause of absences from the working place (National Institute for Occupational Safety and Health (NIOSH), 1999).

The question is why the burnout syndrome is not accepted as a disorder in the international classification systems, while other stress-related disorders are. It is subject of a long and inexhaustible discussion if the burnout syndrome and MDD represent different pathologies with overlapping symptoms or if they describe aspects of the same disorder (Bianchi et al., 2015; Schonfeld and Bianchi, 2015). Depression has been considered as a symptom of burnout (Freudenberger, 1974), as the final state of burnout (Weiskopf, 1980) and as a synonym for burnout (Ficklin, 1983). Meier (Meier, 1984) reported that measures of burnout correlated highly with depression, weakening the support for burnout's discriminant validity. Bianchi et al. 2013 (Bianchi et al., 2013) found no significant difference in the Beck Depression Inventory-II (BDI-II) (Beck, 1988) between depressed and burnout patients. As the BDI scores were similar in the burnout and the MDD group except for one criterion, they concluded that burnout and depression might not be separate pathological entities. Similarly, Gan and colleagues (Gan et al., 2013) showed by means of a double cluster analysis- a method clustering data into meaningful groups and exploring similarities or differences between individual data points in these clusters -that burnout and depression measured by the Maslach Burnout Inventory (MBI) and BDI show a conceptual overlap of $38.7 \%$. Results of the Finnish Health Study 2000 including 3276 employees also showed a marked overlap between burnout and MDD (Ahola et al., 2005). They reported increasing probability of having MDD with higher scores on the MBI burnout scale. Thus, one conclusion was that burnout could be viewed 
as a phase in the development of MDD (Ahola et al., 2005). However, they also concluded that jobrelated burnout and depressive disorders are overlapping but not identical concepts and should be therefore treated differently. There are other contributions supporting the view that MDD and burnout share many common symptoms, but that the characteristic features of these two concepts are distinct. In MDD depressed mood and loss of interest or pleasure are predominant. In burnout demoralization, fatigue and increased irritability are typical (Kakiashvili et al., 2013). Indeed, there is an approach stating MDD as an exclusion criterion for burnout (von Kanel, 2008).

What may be considered as a conceptual discussion is basically an important question in terms of appropriate treatment, therapy and prognosis (Ahola et al., 2005; Ballweg et al., 2013; Kakiashvili et al., 2013). To date, burnout and other chronic stress-related disorders are often treated as depression or not treated at all (Kakiashvili et al., 2013) and no evaluated specific therapy concepts exist.

There are several approaches trying to characterize and contrast burnout and MDD not only in terms of symptoms and etiology, but also by means of biological parameters (Danhof-Pont et al., 2011; Mommersteeg et al., 2006; Onen Sertoz et al., 2008). In this review, the aim is to elaborate similarities and differences between burnout and MDD focusing on two biological correlates of stress: heart rate variability (HRV) and brain-derived neurotrophic factor (BDNF). As BDNF has a crucial role in neuroneogenesis, hippocampal volume is also considered. The typical "stress hormone" cortisol was not incorporated into the present discussion, as there is large impact of heredity on basal free cortisol levels (Bartels et al., 2003) what might explain the large body of inconsistent findings on HPA-axis functioning, i.e. cortisol, in burnout (Mommersteeg et al., 2006). Both HRV and BDNF are at least as crucial in stress response as cortisol. HRV mirrors the autonomic nervous system as it offers immediate and precise information about parasympathetic activity and withdrawal, respectively, and thus about stress reactivity. BDNF is involved in neuronal survival and neurogenesis in the hippocampus, which in turn represents a superordinate authority in stress processing. With the choice of these two important stress parameters as the basis of discussion, 
burnout and depression are thought to be elucidated from the perspective of major pathways of stress response.

\section{Methods}

Literature search was performed in PubMed with following terms: [HRV/heart rate variability AND burnout], [HRV/heart rate variability AND burnout AND depression], [HRV/heart rate variability AND depression AND stress], [BDNF AND burnout], [BDNF AND burnout AND depression], [BDNF AND depression AND stress] and [HRV AND BDNF]. Filters applied were (1) human studies and (2) English or German language. The focus was on articles in which depression and/or burnout were the main pathologies, and original research papers were prioritized to literature reviews and meta-analyses.

\section{Heart Rate Variability}

Heart rate variability (HRV), i.e. the variability of the intervals between two heart beats, is one of the most sensitive measures of the functioning and balance of the autonomic nervous system. Widely used HRV parameters are the standard deviation of the inter-beat intervals (SDNN) and the quantification of the low-(LF) and high-frequency (HF) components by power spectral analysis (Akselrod et al., 1981; Hayano et al., 1991; Task Force of the European Society of Cardiology and the North American Society of Pacing and Electrophysiology, 1996). The HF spectrum is considered a measure of parasympathetic activity, especially the vagal nerve (Berntson et al., 1997; Loerbroks et al., 2010; Pomeranz et al., 1985). In contrast, the interpretation of the LF component has turned out to be rather controversial (Reyes del Paso et al., 2013). The LF band has been originally regarded as a "mixed frequency" representing both parasympathetic and sympathetic nervous system activity (Pagani et al., 1986), and the relation between the LF and HF component, termed LF/HF ratio, has been considered to mirror sympatho-vagal balance and particularly sympathetic modulation (Task Force of the European Society of Cardiology and the North American Society of Pacing and Electrophysiology, 1996). In a recent review, however, the validity of LF as an index of sympathetic 
activity was challenged and it was concluded that the LF component is also predominantly influenced by parasympathetic activity (Reyes del Paso et al., 2013). Therefore, the focus of the following discussions is on changes in parasympathetic measures. Generally, HRV parameters can instantly reflect acute changes in physiologic (McCraty et al., 1995) and psychological states (Shinba et al., 2008) as well as regulatory processes involved in behavioral-emotional, cognitive, and psychosocial activities (Kotov and Revina, 2012). Changes in HRV were observed to be characteristic to a number of mental disorders, including MDD or panic disorders (Gorman and Sloan, 2000; Yeragani et al., 1991; Yeragani et al., 1993). Also social isolation, anger and high emotional stress can significantly alter HRV (Dishman et al., 2000; Horsten et al., 1999).

\section{HRV in relation to chronic work stress and burnout}

There are several studies reporting that stressful work-associated conditions decrease HRV (Delaney and Brodie, 2000; Madden and Savard, 1995; Milosevic et al., 2012). However, there are conflicting results. In a study including white-collar employees no correlation between HRV and the scores of a job stressor questionnaire measuring job difficulty, job quantity, achievement in job, support by colleagues, and job decision latitude was found (Kageyama et al., 1998). In a more recent work higher levels of stress were even related to increased HRV, i.e. increased HF power reflecting higher parasympathetic activity (Quintana et al., 2012). One explanation of this result might be that the subscales of the used questionnaire may not mirror pathological stress. Alternatively, HRV parameters may not reflect simply the degree of stress but rather an individual's strategy to cope with stressful conditions. In a group of first-aid doctors within an advanced burnout process individuals with task-oriented coping strategies showed significantly less signs of emotional stress and higher HRV compared to those with an emotion-oriented coping strategy (Kotov and Revina, 2012). A similar effect of autonomic coping strategies has been reported in a study in which healthy subjects and burnout patients were exposed to a simulated working day scheduled with several cognitive tasks (Zanstra et al., 2006). Healthy subjects demonstrated performance improvement at 
the end of the day, while burnout patients showed a substantial decline. The HRV recordings revealed that the healthy subjects soon increased parasympathetic, i.e. vagal reactivity, while the burnout patients continued to respond with the initial level of parasympathetic reactivity. This result is underpinned by the work of Porges (Porges, 1995a), who suggested a vagal withdrawal in response to increasing task demand in burnout. On the background of these findings, the above cited results of the positive correlation between stress level and HRV (Quintana et al., 2012) may represent the healthy participants' ability to raise parasympathetic activity in response to increasing stress levels. Impairments in parasympathetic reactivity might also be correlated to the chronicity of stress. While acute stress is associated with transitory but flexible vagal withdrawal, in chronic stress parasympathetic reactivity may be fundamentally reduced (Porges, 1995a). In recent studies examining HRV in clinical burnout it was shown that patients exhibited basically reduced parasympathetic activity also without or before stress exposure (de Vente et al., 2015; Lennartsson et al., 2016). In comparison to healthy controls reporting high burnout scores, burnout patients still had significantly lower parasympathetic parameters implying that basic HRV changes develop with chronic stress burden manifested as clinical burnout (Lennartsson et al., 2016).

Occupational stress is often of chronic nature and stressful work conditions not only consist of isolated situational stressors but also of the aftermaths of stressors in the past and anticipated stressful events in the future. These more distant effects involve perseverative cognitive processes, i.e. constant activation of the cognitive representation of stress which is manifested as worry or rumination (Brosschot et al., 2006; Brosschot et al., 2005). Rumination is associated with reduced HRV, i.e. attenuated parasympathetic activity (Pieper et al., 2010) and is considered a characteristic of various affective disorders, such as depression, anxiety disorders, or posttraumatic stress disorder (Brosschot et al., 2005). It is thought to be caused by disinhibition of the normal inhibitory control of sympathetic neural circuits mediated by the prefrontal cortex leading to sympathetic dominance and parasympathetic withdrawal (Brosschot et al., 2007). The extent of vagal withdrawal during ruminative thoughts has been found to be further modulated by certain personality traits (Ottaviani 
et al., 2009; Shinba et al., 2008). Higher depressiveness and especially anxiety in daily life were correlated to decreased HRV responsiveness indicating pathological autonomic rigidity.

\section{HRV in major depressive disorder (MDD)}

Not only depressive personality traits but also depressive mood as in patients with MDD is coupled with autonomic dysfunction. There is a body of evidence that MDD patients have lower HRV (Taylor, 2010), i.e. lower parasympathetic control of the heart (Schwerdtfeger and Friedrich-Mai, 2009). Decreased HRV is one of the most well-known pathophysiological mechanisms that might underlie the risk of cardiovascular diseases in patients with depression (Blasco-Lafarga et al., 2010; Carney et al., 1995; de Jonge et al., 2007; Licht et al., 2008).

Comparable to healthy individuals (Shinba et al., 2008), MDD patients with high scores of trait anxiety showed more reduced HRV, e.g. stronger vagal withdrawal, compared to patients low on trait anxiety (Tulen et al., 1996). In a study involving different subgroups of unmedicated MDD patients MDD without comorbidity, MDD with comorbid panic disorder and/or posttraumatic stress disorder and MDD comorbid with generalized anxiety disorder - decrease in HRV measures was most pronounced in patients with comorbid generalized anxiety disorder (Kemp et al., 2012). As the subgroups did not differ in depression severity, the observed HRV reductions were assumed to be due to anxiety. Thus, anxious anticipation or worry, which is characteristic for generalized anxiety disorder, may lead to chronic withdrawal of parasympathetic activity (Kemp et al., 2012).

\section{HRV in MDD and burnout}

While in MDD reduced HRV based on parasympathetic withdrawal seems to be a consistent result, HRV data in burnout are contradictory and may depend on coping strategy and/ or duration of stress exposure. The duration of chronic stress burden may be the crucial factor why patients with clinical burnout show reduced parasympathetic activity at also at rest, whereas non-clinical subjects with high burnout scores have similar HRV as healthy controls. Based on these findings it might be 
concluded that with increasing chronicity of stress exposure burnout may converge to MDD, strengthening the view of burnout being a pre-stage of MDD (Weiskopf, 1980). In line with this hypothesis, clinical burnout has also been shown to promote the risk of cardiovascular diseases like MDD and reduced parasympathetic vagal activity is considered as the mediating physiological mechanism (de Vente et al., 2015; Melamed et al., 2006). However, in their extensive review considering a variety of physiological systems, Melamed and colleagues (Melamed et al., 2006) have elaborated that the two pathologies may involve different physiological pathways that increase the risk for cardiovascular diseases.

The pathology-overlapping symptoms, rumination and anxiety, emerged to be modulators of HRV. Interestingly, rumination has been found to be a strong predictor of anxiety and was particularly characteristic for individuals with mixed anxiety and depression symptoms (Nolen-Hoeksema, 2000). Anxiety - and rumination (see above) -is regarded as a disinhibition syndrome as it comes along with difficulties in disengaging from the detection of threatening stimuli even when no real threat exists (Thayer et al., 2009). Inhibition of irrelevant or interfering stimuli is essential for appropriate information processing and is one of the principal functions of the prefrontal cortex. Moreover, the prefrontal cortex may influence HRV via the vagus as described in the neurovisceral integration model (Thayer et al., 2009). Dysfunctions in the prefrontal cortex may thus lead to the disinhibition syndromes associated with chronic vagal withdrawal.

Prefrontal dysregulations may also be crucial to burnout. Namely functional connectivity between the medial prefrontal cortex and the amygdala - two key structures mediating reactions to stressors has been shown to be weaker in subjects suffering from chronic occupational stress (Golkar et al., 2014).

\section{Brain-derived neurotrophic factor}

Brain-derived neurotrophic factor (BDNF) is a neurotrophin that has different functions through life span. In early life it regulates neuronal development and activity that could result in varying 
behavioral outcomes (Perea et al., 2012). Later in life it is involved in the survival and differentiation of the central nervous system (Dechant and Neumann, 2002; Lipsky and Marini, 2007; Waterhouse and $\mathrm{Xu}, 2009)$. Moreover, BDNF has been demonstrated to play an important role in mechanisms of memory acquisition and consolidation, suggesting that it might be a crucial regulator of synaptic plasticity and neurogenesis (Figurov et al., 1996; Korte et al., 1995; Lu, 2003).

BDNF is expressed in cortical and subcortical areas, primarily in regions of the brain involved in mood regulation such as the frontal cortex, striatum, and thalamus (Bath and Lee, 2006) and particularly in the hippocampus (Lu and Gottschalk, 2000).

In humans, brain BDNF levels can only be assessed in postmortem studies (Chen et al., 2001). However there are results indicating that BDNF levels in blood (Lang et al., 2007) and also in saliva (Mandel et al., 2011) might reflect the BDNF levels in the brain. Since the protein can cross the blood brain-barrier in both directions, circulating BDNF is presumed to correlate with cortical BDNF concentrations (Sartorius et al., 2009).

A critical influence on circulating BDNF is hypothesized to be exerted by a single nucleotide polymorphism, i.e. the substitution of the amino acid valine to methionine in the BDNF gene resulting in the two alleles: Val and Met (Clasen et al., 2011; Terracciano et al., 2010). The allele frequencies are consistently reported to be in the Hardy-Weinberg equilibrium with the Val/Val genotype being the most prevalent and the Met/Met genotype being rather infrequent. The Val/Val genotype has been associated with increased gene expression relative to genotypes comprising a Met allele, i.e. the Val/Met and Met/Met genotypes (McHughen et al., 2010). However, there are reports concluding that the Met allele may be protective as it seems to improve BDNF processing (Sen et al., 2003).

BDNF in relation to chronic (occupational) stress and burnout

BDNF is thought to protect against stress-induced neuronal damage (Radecki et al., 2005). However, circulating BDNF in turn is sensitive to stress (Mattson et al., 2004). Occupational stress has 
repeatedly been shown to be correlated with reduced BDNF levels. The higher the perceived psychological job stress, the lower were the BDNF serum levels in healthy employees (Mitoma et al., 2008; Okuno et al., 2011). In a group of medical staff fulfilling the criteria for the burnout syndrome BDNF levels were significantly lower compared to healthy colleagues. Interestingly, there was no such difference in cortisol, the so-called stress hormone and end product of the HPA-axis between groups. These findings may indicate that rather a BDNF pathway than the HPA-axis may be involved in the burnout process (Onen Sertoz et al., 2008).

The Val/Met polymorphism seems to have an impact on stress vulnerability (Frodl et al., 2007; Joffe et al., 2009). In a large group exposed to prolonged psychosocial stress, individuals with the Val/Val genotype have shown higher scores of depressive symptoms (Jiang et al., 2013). Carriers of a Val allele have also shown a higher degree of neuroticism (Lang et al., 2005; Sen et al., 2003), a depression-related personality trait, which reflects stress sensitivity and emotional instability (Kendler et al., 2006). However, there are conflicting results finding neuroticism neither to be associated with the Val/Met polymorphism nor with low BDNF levels (Terracciano et al., 2010). Yet another study reported that subjects carrying the Met allele have a higher extent of neuroticism and have more sub-threshold symptoms of depression (Joffe et al., 2009). Comparably, under conditions of life stress exclusively Met allele carriers demonstrated increased rumination, which is a known predictor for depression (Clasen et al., 2011).

As BDNF has an important role in development, stress occurring early in life may have special impact. Investigations of the interaction between physical and psychological childhood maltreatment and the Val/Met polymorphism demonstrated that affected individuals carrying a Met allele scored higher in adult depressive symptoms compared to those with the Val/Val genotype (Aguilera et al., 2009; Gatt et al., 2009; Perea et al., 2012). However, Gatt and colleagues (Gatt et al., 2009) proposed that both the Val and the Met allele, respectively, can confer risk to symptoms of mental disorders when a subject is exposed to childhood stress. They found that in individuals with a history of childhood 
stress the $\mathrm{Val} / \mathrm{Val}$ genotype is associated with syndromal anxiety, while in Met allele carriers early life stress predicted higher syndromal depression as well as mixed symptoms of depression and anxiety. Similarly, the Met allele and the homozygous Met variant are associated with higher trait anxiety in adults without a history of childhood stress (Jiang et al., 2005). However, another study found the opposite tendency of the Val allele being correlated to anxiety-related personality (Lang et al., 2005).

$B D N F$ in $M D D$

There are several studies that found decreased BDNF levels in patients with depression (Gonul et al., 2005; Karege et al., 2002; Shimizu et al., 2003) and it has been reported that antidepressant treatment restores BDNF levels (Brunoni et al., 2008; Chen et al., 2001; Gonul et al., 2005; Sen et al., 2008). These observations led to the "neurotrophic hypothesis of depression" stating that decreased expression of BDNF could contribute to depression and that antidepressants mediate their therapeutic benefit by upregulating BDNF levels (Duman and Monteggia, 2006).

Similar to the non-clinical groups discussed above, the Val/Met polymorphism is investigated in combination with childhood stress as a predictive factor for major depression.

Carriers of a Met allele with a history of childhood adversity showed increased risk for lifetime depression (Juhasz et al., 2011). An accumulation of the Met allele was observed in depressed women but not in men with a history of childhood stress, indicating gender-specific interactions (Lavebratt et al., 2010). Interestingly, the Met allele was associated with reduced rumination, which in turn is supposed to protect from depressive symptoms (Juhasz et al., 2011). Conversely, the $\mathrm{Val} /$ Val genotype seemed to promote rumination, although this genotype does not represent a risk factor for depression. These findings are in contrast to healthy individuals affected by adult stress (discussed above), where the Met allele increases the tendency for rumination (Clasen et al., 2011). Patients with MDD are supposed to have reduced hippocampal volumes compared to healthy individual, which seems to be more pronounced in Met allele carriers (Frodl et al., 2007; Molendijk et 
al., 2012; Montag et al., 2009). More specifically, Carballedo and colleagues (Carballedo et al., 2013) observed, that only Met allele carriers with a history of childhood stress had significantly smaller hippocampal volumes. Met-allele carriers without such a history had even larger hippocampal volumes compared to the Val/Val genotype. The interaction between the Met allele and childhood stress was reported in both MDD patients and healthy controls, respectively, indicating that this finding may be independent from diagnosis. There are findings proposing that the Met allele per se is linked to smaller hippocampal volumes, regardless of childhood history and diagnosis (Molendijk et al., 2012).

\section{$B D N F$ in MDD and burnout}

While circulating BDNF levels were repeatedly found to be lowered in burnout and depression, results concerning the effect of the Val/Met polymorphism are rather inconsistent for both pathologies. However, the polymorphism seems to exert an influence in combination with childhood stress, which is discussed as a potent modulator of neural plasticity in connection to BDNF. Strong childhood stressors are thought to alter central neurobiological systems, such as HPA axis activity, and lead to higher stress sensitivity and thus to predispose individuals to adult-onset depression (Nemeroff, 2004).

Patients with acute MDD being homozygous Met allele carriers were observed to have higher blood levels of cortisol, while the presence of at least one Val allele is sufficient to avoid HPA axis dysregulation (Schule et al., 2006). In burnout, there were no indices that BDNF may modify HPA-axis activity (Onen Sertoz et al., 2008). As in this burnout group the BDNF genotype was not determined and the Val allele is far more prevalent than the Met allele, higher stress-reactivity of Met/Met genotypes might have been overlaid. 


\section{Hippocampal volume}

The hippocampus is part of the limbic system and plays a crucial role in learning and memory, fear conditioning as well as neuroendocrine regulation (Sapolsky, 2000b). It is one of the brain structures where adult neurogenesis occurs (Gould et al., 1999). As it exhibits large quantities of corticosteroid receptors, it is a primary neural target for glucocorticoids such as cortisol (Sapolsky, 2000a).Therefore it is not surprising that there is a large body of research showing that stress plays a crucial role in the proliferation of neurons and synaptic plasticity in the hippocampus (Swaab et al., 2005).

\section{Hippocampal volume and burnout}

As discussed above, the hippocampal volume is influenced by genetic variation such as the BDNF Val/Met polymorphism (Frodl et al., 2007; Molendijk et al., 2012; Montag et al., 2009). Moreover, environmental factors like chronic stress may influence the brain via various mechanisms, such as decreased neurogenesis (Duman, 2004). Because of the hippocampus' particularly high sensitivity to stress, Eriksson and Wallin (Eriksson and Wallin, 2004) have proposed that stress-mediated decrease in adult hippocampal neurogenesis provides the biological basis of altered brain plasticity in chronic stress-related syndromes like burnout. They suggest that stress-induced HPA-axis hyperactivity results in excessive cortisol exposure and subsequent neurotoxicity leading to neurodegeneration in the hippocampus (Eriksson and Wallin, 2004; Sapolsky, 2000b).The loss of hippocampal neurons in turn results in reduced inhibition of the stress response. However, there is a study showing that in response to intermediate stressful life events the hippocampal volume may transiently increase. This may represent a short term compensatory mechanism to inhibit stress response by boosted neurogenesis (Zannas et al., 2013). As it has been repeatedly observed that chronic stress leads to a reduction in hippocampal volume, the authors concluded that enduring negative stressful life events may have differential short- and long term effects on the hippocampus. Recent magnetic resonance imaging studies found no differences in the structural volume of the hippocampus between patients suffering from chronic occupational stress for at least one year and healthy controls (Blix et al., 2013; 
Savic, 2015). This outcome might also be interpreted with regard to delayed effects of stress on the hippocampus, indicating that the duration of stress exposure was not long enough for visible morphological changes. This is additionally supported by the work of Zannas and colleagues (Zannas et al., 2013) who did not report a relationship between changes in the number of negative stressful life events and a change in hippocampal volume over a period of two years. This "negative" result suggests that putative neurotoxic effects of cortisol may involve slow processes which take longer periods of time.

\section{Hippocampal volume and $M D D$}

There is strong evidence that clinical MDD is associated with neuronal abnormalities in the hippocampus and other brain regions involved in emotional processing and stress-responsiveness (Koolschijn et al., 2009). It has been shown that the longer the duration of depressive episodes, the smaller hippocampal volumes (MacQueen et al., 2003). Furthermore, it has been observed that the more severe the morphologic changes in the hippocampus the more severe the outcome of depression (Frodl et al., 2008).

Irrespective of the BDNF Val/Met polymorphism, it is suggested that repeated childhood stress causes "limbic scars", i.e. volume reductions in the hippocampus persisting into adulthood, also in subjects who do not develop MDD (Dannlowski et al., 2012; Frodl et al., 2010). In a group of women with MDD, those who were exposed to childhood abuse had smaller hippocampal volumes compared to those without a history (Vythilingam et al., 2002). Thus, via reduced hippocampal volume and function, childhood stress leads to permanent changes in the HPA- axis responsiveness to stress and increased risk for developing depression (Heim et al., 2000). In individuals who have experienced childhood stress, the development of disorders in later life might also depend on the kind of stressor, e.g., chronic stress could rather leads to the development of depression, while acute and traumatizing events could result in PTSD (Dannlowski et al., 2012). 
Hippocampal volume in burnout and MDD

With regard to the hippocampal volume, MDD seems to be a consequence of chronic stress, i.e. chronically elevated HPA-axis activity leading to the suppression of neurogenesis (Duman et al., 2000) and increased neuronal apoptosis (Dygalo et al., 2012).

However, although reduced hippocampal neurogenesis is assumed to be a biological basis of burnout and one of the pathways for depression and other neuropsychiatric disorders, there is a large variability in hippocampal volume also in healthy adults (Lupien et al., 2007). Reduced hippocampal volume found in connection to psychiatric illnesses could also constitute a pre-determined difference (e.g. the Val/Met polymorphism) that increases an individuals' vulnerability to stress and mental disorders.

\section{Discussion}

The aim of this literature search and review was to compare and contrast the burnout syndrome and MDD on the basis of the biomarkers HRV, BDNF as well as hippocampal volume. A differentiation of these two pathologies is of particular interest with regard to the affected individual's awareness of disease and appropriate treatment.

Concerning HRV it was revealed that parasympathetic reactivity might be correlated to the chronicity of stress and that long term stress may lead to fundamental vagal withdrawal. Healthy individuals exposed to chronic stress may show initially increased parasympathetic activity if they apply appropriate coping strategies. However, if they process stressful conditions with a tendency to rumination or anxiety, HRV, i.e. parasympathetic tone is decreased. In MDD HRV has consistently been reported to be decreased which is thought to promote the concomitant risk for cardiovascular diseases. Similar to burnout or chronic stress, MDD patients with symptoms of anxiety show stronger parasympathetic withdrawal compared to patients without anxiety. 
Both burnout and MDD patients show reduced serum levels of BDNF. However, BDNF levels in stressed individuals were reported to be higher than in patients with MDD (Mitoma et al., 2008). Quite inconclusive is the role and influence of the Val/Met polymorphism. In healthy individuals suffering from chronic stress, the Met allele seems to promote rumination, which is a risk factor for depression and anxiety (Beevers et al., 2009; Clasen et al., 2011). In contrast, in MDD the Met allele was associated with less rumination (Juhasz et al., 2011). Furthermore, there was no consistent finding that either allele is associated with decreased hippocampal volume, despite the crucial role of BDNF in hippocampal neurogenesis.

Hippocampal volume is rather influenced by childhood stress and the duration of stress in adulthood. Short term stress has found to be compensated by a transient increase in hippocampal volume. In burnout, which is assumed to result from long term stress, no morphological changes in the hippocampus were found. Therefore, it was hypothesized that a decrease in neurogenesis caused by stress-mediated neurotoxicity might be a prolonged process than immediate compensatory mechanisms. Analogously, hippocampal volume in MDD decreases with the duration of the depressive episode which is also thought to be an effect of glucocorticoid neurotoxicity. Childhood stress may cause structural alterations, "limbic scars" that lead to greater stress sensitivity.

Taken together, the parameters HRV, more precisely parasympathetic activity, and hippocampal volume seem to provide information about the chronicity of stress. Healthy individuals may react to intermediate stress by an increase of vagal tone (Quintana et al., 2012) and boosted neurogenesis in the hippocampus (Zannas et al., 2013) in order to meet the additional requirements. There is no comparable observation concerning serum BDNF levels, which negatively correlate with increasing degree of occupational stress (Mitoma et al., 2008; Okuno et al., 2011).

In burnout, which is thought to be a manifestation of processes associated with chronic stress, as well as in MDD the former compensatory mechanisms may not be longer efficient. Both pathologies are accompanied with lowered BDNF levels, parasympathetic withdrawal and - depending on the progress of disease - smaller hippocampal volumes, making their discrimination a challenge. The 
issue is aggravated by the fact that the biological markers may be further modulated by other factors such as anxiety, rumination and childhood stress, which are cumulated in both disorders. Therefore, single parameters may not be appropriate to discriminate burnout and MDD, and rather combinations of various geno- and phenotypic parameters and environmental factors are needed. In one of the few studies investigating both BDNF and HRV in stress-related disorders, it has been shown that the BDNF Val/Met polymorphism has an impact on autonomic functions (Yang et al., 2010). In individuals with the Met/Met genotype parasympathetic activity was observed to be poorer compared to Val allele carriers. BDNF may be a potential modulator of the parasympathetic nervous system as it can activate the synthetization of acetylcholine, which is an essential parasympathetic neurotransmitter (Burgess and Aubert, 2006). As the Met allele has been associated with reduced BDNF gene expression (McHughen et al., 2010), lower vagal modulation of individuals with the Met/Met genotype might be based on lowered BDNF production.

Parasympathetic withdrawal is often accompanied by increased sympathetic activity, which in turn is associated with anxiety, especially trait anxiety (Miu et al., 2009; Mujica-Parodi et al., 2009; Shinba et al., 2008). However, concerning the BDNF polymorphism underlying trait anxiety a body of conflicting results exists, too. Anxiety-related phenotypes have been shown to be associated with the Met allele (Jiang et al., 2005), the Val allele (Lang et al., 2005) or not to be correlated to either (Arias et al., 2012; Yang et al., 2010). In a meta-analysis it emerged that neuroticism, which is an anxiety trait and also an important risk factor for MDD, is decreased in healthy individuals carrying at least one Met allele (Frustaci et al., 2008). The inconclusive results of the various studies investigating the impact of BDNF polymorphism on anxiety call a genuine association into question. Generally, when investigating the relationship between disorders and BDNF polymorphism, it is important to consider that the frequency of the Met and Val alleles is comparable in healthy controls and MDD patient groups (Carballedo et al., 2013). However, although the BDNF gene polymorphism alone might not be a potent biomarker, it may be a candidate partner for gene-gene interactions underlying the risk for developing anxiety and depression. It could be demonstrated that individuals with a Met/Met 
genotype who also were carriers of a specific variant of the serotonin transporter gene, exhibited significantly higher scores for harm avoidance, which is an anxiety-related trait (Arias et al., 2012). This finding is in line with the well documented reciprocal interaction between BDNF and serotonin (Duman, 2002) and the evident role of the serotonin system in the development of both mood and anxiety disorders (Ressler and Nemeroff, 2000). Genetic factors have been estimated to explain 37\% of the risk to develop MDD (Sullivan et al., 2000). Environmental influences that significantly add to the vulnerability are childhood stress and negative stressful life events (Lavebratt et al., 2010; Sjoholm et al., 2009). Indeed, an extensive review considering 21 studies provides support that interactions between genes and childhood adversity contribute to the risk for depression and anxiety outcomes (Nugent et al., 2011). In line with this, the genes $x$ childhood adversity interaction and its impact on the brain and autonomic nervous systems has been proposed to be a starting condition for the development pathway to depression and anxiety (Gatt et al., 2009). It was revealed that Met allele carriers who were exposed to childhood adversity had significantly reduced gray matter volumes in the hippocampus and the lateral prefrontal cortex (PFC), which in turn was associated with higher depression scores. On the other hand, the combination of the homozygous Val/Val genotype and childhood adversity predicted increased gray matter volumes in the amygdala and the medial PFC and was accompanied with autonomic arousal, i.e. reduced HRV and higher anxiety (Gatt et al., 2009). Not only structural abnormalities, but also functional dysregulation of limbic output, namely delayed inhibition of emotional arousal and increased autonomic excitation was found in trait anxiety (Mujica-Parodi et al., 2009). Consistently, functional alterations were shown in the structures of the frontoamygdala circuitry (Malter Cohen et al., 2013), which is involved in threat processing and vigilance (Lupien et al., 2009). These alterations were closely related to the BDNF genotype. Met allele carriers show atypical frontoamygdala activity, namely less activation in the ventromedial PFC and greater amygdala activity during fear extinction than non-carriers. Thus, there is less inhibition of the amygdala by the ventromedial PFC resulting in increased fear (Phelps et al., 2004; Soliman et al., 2010). Dysregulation of functional connectivity between the medial prefrontal 
cortex and the amygdala has also been proposed to play a key role in burnout (Golkar et al., 2014). Interestingly, the weaker functional connectivity found in burnout patients was associated with higher scores in the items concerning anxiety and poor sleep of a depression questionnaire, but not with depression per se. Thus, future research distinguishing burnout and MDD may focus on structural and functional alterations of the frontoamygdala circuitry as well as on its correlation to the BDNF genotype.

Another approach in differentiating burnout and MDD might deal with the functional aspect of the two pathologies, especially with adaptation to stressful situations. When regarded from a functional or evolutionary point of view, depression may represent a form of coping strategy or defense as it promotes escape and avoidance of stressful situations (Nesse, 2000). In their extensive review, Korte and colleagues (Korte et al., 2005) distinguish two trait types, Hawks and Doves, which evolved throughout the animal kingdom through natural selection. Hawks and Doves differ in the adaptation of their nervous, immune as well as hormonal system and can be characterized by their opposing behavior. Hawks are rather aggressive, use proactive coping strategies and have high sympathetic reactivity. In contrast, Doves are cautious and show reactive coping. They are more sensitive in processing sensory input and have higher awareness of danger, what makes them vulnerable to develop depression and anxiety disorders. Furthermore, Doves are designated by a hyperactive HPA axis and consequently higher glucocorticoid levels, and by increased parasympathetic activity. Notably, it is the dorsal part of the vagus that contributes to higher parasympathetic reactivity. According to the polyvagal theory (Porges, 1995b), the dorsal vagus evokes the freezing response in the presence of a strong stressor.

While Dove-typed individuals may be prone to develop depression, Hawks may rather burn out. Indeed, Hawks share common features with the Type A personality (Friedman and Rosenman, 1974), which is described as (over-)ambitious, extremely competitive, impatient and hostile, and has also been linked to burnout (Maslach et al., 2001). However, more recent studies found no correlation between Type A and burnout (Alarcon et al., 2009), and proposed rather personality disorders to 
correlate with burnout (Berberich et al., 2012). Thus, although offering an interesting approach, the Dove and Hawk concept may not be directly applied to the differentiation of burnout and MDD.

Both, burnout and MDD are thought to be consequences of chronic stress. Enduring and repeated exposure to (psychosocially) stressful situations demands permanent activation of the sympathetic nervous system and the HPA-axis, which end up in a maladaptive process referred to as allostatic load (McEwen and Stellar, 1993). A possible measure to quantify allostatic load is the Allostatic Load Index (ALI) developed in 1997 by Seeman and colleagues (Seeman et al., 1997). Originally, the index was based on ten physiological and physical parameters, among them blood pressure, cholesterol, waist-to-hip ratio, dehydroepiandrosteronesulfate (DHEA-S), as well as urinary cortisol, epinephrine and norepinephrine. To date, there are various studies applying altered combinations of biomarkers to determine the ALI (Mauss et al., 2015). A recent work proposed a clinical ALI that is integrating dysregulated biomarkers observed in burnout research, namely morning and stress reactive cortisol and $\alpha$-amylase (Juster et al., 2011). They demonstrated that their specific ALI was reliably correlated to increased chronic stress and burnout symptoms, but not to depressive symptoms. This result enforces the proposal formulated above, that not a single but rather an appropriate combination of biomarkers is more naturalistic and sensitive to differentiate burnout and MDD. In this review a number of state and trait candidate parameters emerged that could be assessed in addition to the traditional ALI to elaborate a biological profile of burnout and MDD, such as HRV, especially vagal activity, BDNF level with regard to the Val/Met polymorphism, structure and functioning of the frontoamygdala circuit, trait anxiety and events of childhood stress. Such a biological signature (Gruenewald et al., 2006) constituted by state and trait biomarkers may provide precious information about the current physiological strain, vulnerability for and coping with stress and may even offer a tool for diagnosis and suggestions for appropriate treatment.

However, there may be a number of other suitable target parameters not discussed in this review. Among these are various mediators of the immune systems (Danhof-Pont et al., 2011), a major metabolite of noradrenaline, 3-methoxy-4-hydroxyphenylglycol (MHPG), which is related to 
depression-associated personality traits as well as to MDD (Okuno et al., 2011), EEG-based biomarkers (Tement et al., 2015), or the genotype of the serotonin transporter gene (SLC6A4) (Clasen et al., 2011; Gutierrez et al., 2015). Another factor that has strong impact and must be considered in future studies is gender. Sex steroid hormones have been shown to regulate BDNF gene expression in different ways and the phenotypes - e.g. the vulnerability to stress - of the BDNF Val/Met polymorphism have been demonstrated to be gender-specific (Chang et al., 2014; Shalev et al., 2009). Moreover, there are gender differences in the volume of brain structures with implication to the susceptibility to stress-related disorders (Yamasue et al., 2008). However, identifying specific discriminating parameters still do not overcome the intrinsic problem that burnout is not a classified diagnosis and depression is a very heterogeneous disorder with different forms and courses and a high variance regarding the occurrence of the first episode. Also the term chronic stress, which is thought to be an initiator of both disorders, is elusive and has a variety of different meanings and dimensions (McEwen and Norton Lasley, 2002).

Despite the mentioned obstacles, it is promising and worth looking for discrimination parameters and elaborating specific biological signatures of burnout and MDD as it may help to customize treatment to the two mental health problems which are among the major causes for disability at work (National Institute for Occupational Safety and Health (NIOSH), 1999) and significantly contribute to the overall global burden of disease (World Health Organisation, October 2015). The most seminal approach and recommended subject for extensive research is to find conclusive combinations of parameters that integrate candidate genes, brain (structure and function) and physiological, environmental as well as temporal factors, which are specific to burnout and MDD, respectively.

\section{References}

Aguilera, M., Arias, B., Wichers, M., Barrantes-Vidal, N., Moya, J., Villa, H., van Os, J., Ibanez, M.I., Ruiperez, M.A., Ortet, G., Fananas, L., 2009. Early adversity and 5-HTT/BDNF genes: new evidence of 
gene-environment interactions on depressive symptoms in a general population. Psychological medicine 39, 1425-1432.

Ahola, K., Honkonen, T., Isometsa, E., Kalimo, R., Nykyri, E., Aromaa, A., Lonnqvist, J., 2005. The relationship between job-related burnout and depressive disorders--results from the Finnish Health 2000 Study. Journal of affective disorders 88, 55-62.

Akselrod, S., Gordon, D., Ubel, F.A., Shannon, D.C., Berger, A.C., Cohen, R.J., 1981. Power spectrum analysis of heart rate fluctuation: a quantitative probe of beat-to-beat cardiovascular control. Science (New York, N.Y.) 213, 220-222.

Alarcon, G., Eschleman, K.J., Bowling, N.A., 2009. Relationships between personality variables and burnout: A meta-analysis. Work \& Stress 23, 244-263.

American Psychiatric Association, 2000. Diagnostic and statisticalmanual of mental disorders, 4th ed, Washington, DC.

Arias, B., Aguilera, M., Moya, J., Saiz, P.A., Villa, H., Ibanez, M.I., Garcia-Portillo, M.P., Bobes, J., Ortet, G., Fananas, L., 2012. The role of genetic variability in the SLC6A4, BDNF and GABRA6 genes in anxiety-related traits. Acta psychiatrica Scandinavica 125, 194-202.

Ballweg, T., Seeher, C., Tschitsaz, A., Bridler, R., Cattapan, K., 2013. SymBalance: Ein theoriebasiertes, integratives Therapiekonzept zur Behandlung von Burnout. Swiss Archives of Neurology and Psychiatry 164, 170-177.

Bartels, M., Van den Berg, M., Sluyter, F., Boomsma, D.I., de Geus, E.J., 2003. Heritability of cortisol levels: review and simultaneous analysis of twin studies. Psychoneuroendocrinology 28, 121-137. Bath, K.G., Lee, F.S., 2006. Variant BDNF (Val66Met) impact on brain structure and function. Cognitive, affective \& behavioral neuroscience 6, 79-85.

Beck, A.T., Steer, R.A., Garbin, M.G., 1988. Psychometric properties of the Beck Depression Inventory: Twentyfive years of evaluation. Clinical Psychology Review 8, 77-100.

Beevers, C.G., Wells, T.T., McGeary, J.E., 2009. The BDNF Val66Met polymorphism is associated with rumination in healthy adults. Emotion (Washington, D.C.) 9, 579-584.

Berberich, G., Zaudig, M., Hagel, E., Konermann, J., Piesbergen, C., Hauke, W., Krauseneck, T., Ruppert, S., Unger, H., 2012. Klinische Prävalenz von Persönlichkeitsstörungen und akzentuierten Persönlichkeitszügen bei stationären Burnout-Patienten. Persönlichkeitsstörungen: Theorie und Therapie 16, 85-95.

Berntson, G.G., Bigger, J.T., Jr., Eckberg, D.L., Grossman, P., Kaufmann, P.G., Malik, M., Nagaraja, H.N., Porges, S.W., Saul, J.P., Stone, P.H., van der Molen, M.W., 1997. Heart rate variability: origins, methods, and interpretive caveats. Psychophysiology 34, 623-648.

Bianchi, R., Boffy, C., Hingray, C., Truchot, D., Laurent, E., 2013. Comparative symptomatology of burnout and depression. J Health Psychol 18, 782-787.

Bianchi, R., Schonfeld, I.S., Laurent, E., 2015. Burnout-depression overlap: a review. Clin Psychol Rev 36, 28-41.

Blasco-Lafarga, C., Martinez-Navarro, I., Sisamon, M.E., Caus, N., Yanguez, E., Llorens-Soriano, P., 2010. Linear and nonlinear heart rate dynamics in elderly inpatients. Relations with comorbidity and depression. Medicina (Kaunas, Lithuania) 46, 393-400.

Blix, E., Perski, A., Berglund, H., Savic, I., 2013. Long-term occupational stress is associated with regional reductions in brain tissue volumes. PloS one 8 , e64065.

Bouma, E.M., Riese, H., Ormel, J., Verhulst, F.C., Oldehinkel, A.J., 2011. Self-assessed parental depressive problems are associated with blunted cortisol responses to a social stress test in daughters. The TRAILS Study. Psychoneuroendocrinology 36, 854-863.

Brosschot, J.F., Gerin, W., Thayer, J.F., 2006. The perseverative cognition hypothesis: a review of worry, prolonged stress-related physiological activation, and health. Journal of psychosomatic research 60, 113-124.

Brosschot, J.F., Pieper, S., Thayer, J.F., 2005. Expanding stress theory: prolonged activation and perseverative cognition. Psychoneuroendocrinology 30, 1043-1049. 
Brosschot, J.F., Van Dijk, E., Thayer, J.F., 2007. Daily worry is related to low heart rate variability during waking and the subsequent nocturnal sleep period. International journal of psychophysiology : official journal of the International Organization of Psychophysiology 63, 39-47.

Brunoni, A.R., Lopes, M., Fregni, F., 2008. A systematic review and meta-analysis of clinical studies on major depression and BDNF levels: implications for the role of neuroplasticity in depression. The international journal of neuropsychopharmacology / official scientific journal of the Collegium Internationale Neuropsychopharmacologicum (CINP) 11, 1169-1180.

Burgess, A., Aubert, I., 2006. Polysialic acid limits choline acetyltransferase activity induced by brainderived neurotrophic factor. Journal of neurochemistry 99, 797-806.

Carballedo, A., Morris, D., Zill, P., Fahey, C., Reinhold, E., Meisenzahl, E., Bondy, B., Gill, M., Moller, H.J., Frodl, T., 2013. Brain-derived neurotrophic factor Val66Met polymorphism and early life adversity affect hippocampal volume. American journal of medical genetics. Part B, Neuropsychiatric genetics : the official publication of the International Society of Psychiatric Genetics 162B, 183-190. Carney, R.M., Saunders, R.D., Freedland, K.E., Stein, P., Rich, M.W., Jaffe, A.S., 1995. Association of depression with reduced heart rate variability in coronary artery disease. The American journal of cardiology 76, 562-564.

Chang, C.C., Chang, H.A., Chen, T.Y., Fang, W.H., Huang, S.Y., 2014. Brain-derived neurotrophic factor (BDNF) Val66Met polymorphism affects sympathetic tone in a gender-specific way.

Psychoneuroendocrinology 47, 17-25.

Chen, B., Dowlatshahi, D., MacQueen, G.M., Wang, J.F., Young, L.T., 2001. Increased hippocampal BDNF immunoreactivity in subjects treated with antidepressant medication. Biological psychiatry 50 , 260-265.

Clasen, P.C., Wells, T.T., Knopik, V.S., McGeary, J.E., Beevers, C.G., 2011. 5-HTTLPR and BDNF Val66Met polymorphisms moderate effects of stress on rumination. Genes, brain, and behavior 10 , 740-746.

Danhof-Pont, M.B., van Veen, T., Zitman, F.G., 2011. Biomarkers in burnout: a systematic review. Journal of psychosomatic research 70, 505-524.

Dannlowski, U., Stuhrmann, A., Beutelmann, V., Zwanzger, P., Lenzen, T., Grotegerd, D., Domschke, K., Hohoff, C., Ohrmann, P., Bauer, J., Lindner, C., Postert, C., Konrad, C., Arolt, V., Heindel, W., Suslow, T., Kugel, H., 2012. Limbic scars: long-term consequences of childhood maltreatment revealed by functional and structural magnetic resonance imaging. Biological psychiatry 71, 286-293. de Jonge, P., Mangano, D., Whooley, M.A., 2007. Differential association of cognitive and somatic depressive symptoms with heart rate variability in patients with stable coronary heart disease: findings from the Heart and Soul Study. Psychosomatic medicine 69, 735-739. de Vente, W., van Amsterdam, J.G., Olff, M., Kamphuis, J.H., Emmelkamp, P.M., 2015. Burnout Is Associated with Reduced Parasympathetic Activity and Reduced HPA Axis Responsiveness, Predominantly in Males. Biomed Res Int 2015, 431725.

Dechant, G., Neumann, H., 2002. Neurotrophins. Advances in experimental medicine and biology 513, 303-334.

Delaney, J.P., Brodie, D.A., 2000. Effects of short-term psychological stress on the time and frequency domains of heart-rate variability. Perceptual and motor skills 91, 515-524.

Dishman, R.K., Nakamura, Y., Garcia, M.E., Thompson, R.W., Dunn, A.L., Blair, S.N., 2000. Heart rate variability, trait anxiety, and perceived stress among physically fit men and women. International journal of psychophysiology : official journal of the International Organization of Psychophysiology $37,121-133$.

Duman, R.S., 2002. Pathophysiology of depression: the concept of synaptic plasticity. European psychiatry : the journal of the Association of European Psychiatrists 17 Suppl 3, 306-310.

Duman, R.S., 2004. Depression: a case of neuronal life and death? Biological psychiatry 56, 140-145.

Duman, R.S., Malberg, J., Nakagawa, S., D'Sa, C., 2000. Neuronal plasticity and survival in mood disorders. Biological psychiatry 48, 732-739.

Duman, R.S., Monteggia, L.M., 2006. A neurotrophic model for stress-related mood disorders. Biological psychiatry 59, 1116-1127. 
Dygalo, N.N., Kalinina, T.S., Bulygina, V.V., Shishkina, G.T., 2012. Increased expression of the antiapoptotic protein $\mathrm{Bcl}-\mathrm{xL}$ in the brain is associated with resilience to stress-induced depression-like behavior. Cellular and molecular neurobiology 32, 767-776.

Eggers, A.E., 2007. Redrawing Papez' circuit: a theory about how acute stress becomes chronic and causes disease. Medical hypotheses 69, 852-857.

Eriksson, P.S., Wallin, L., 2004. Functional consequences of stress-related suppression of adult hippocampal neurogenesis - a novel hypothesis on the neurobiology of burnout. Acta neurologica Scandinavica 110, 275-280.

Ficklin, T., 1983. Doing burnout. Personnel and Guidance Journal 61, 578-579.

Figurov, A., Pozzo-Miller, L.D., Olafsson, P., Wang, T., Lu, B., 1996. Regulation of synaptic responses to high-frequency stimulation and LTP by neurotrophins in the hippocampus. Nature 381, 706-709. Freudenberger, H.J., 1974. Staff Burn-Out. Journal of social issues 30, 159-165.

Friedman, M., Rosenman, R., 1974. Type A behavior and your heart. Knopf, New York.

Frodl, T., Reinhold, E., Koutsouleris, N., Reiser, M., Meisenzahl, E.M., 2010. Interaction of childhood stress with hippocampus and prefrontal cortex volume reduction in major depression. Journal of psychiatric research 44, 799-807.

Frodl, T., Schule, C., Schmitt, G., Born, C., Baghai, T., Zill, P., Bottlender, R., Rupprecht, R., Bondy, B., Reiser, M., Moller, H.J., Meisenzahl, E.M., 2007. Association of the brain-derived neurotrophic factor Val66Met polymorphism with reduced hippocampal volumes in major depression. Archives of general psychiatry 64, 410-416.

Frodl, T.S., Koutsouleris, N., Bottlender, R., Born, C., Jager, M., Scupin, I., Reiser, M., Moller, H.J., Meisenzahl, E.M., 2008. Depression-related variation in brain morphology over 3 years: effects of stress? Archives of general psychiatry 65, 1156-1165.

Frustaci, A., Pozzi, G., Gianfagna, F., Manzoli, L., Boccia, S., 2008. Meta-analysis of the brain-derived neurotrophic factor gene (BDNF) Val66Met polymorphism in anxiety disorders and anxiety-related personality traits. Neuropsychobiology 58, 163-170.

Gan, Y., Kakiashvili, T., Koczkodaj, W.W., Li, F., 2013. A note on relevance of diagnostic classification and rating scales used in psychiatry. Computer methods and programs in biomedicine 112, 16-21. Gatt, J.M., Nemeroff, C.B., Dobson-Stone, C., Paul, R.H., Bryant, R.A., Schofield, P.R., Gordon, E., Kemp, A.H., Williams, L.M., 2009. Interactions between BDNF Val66Met polymorphism and early life stress predict brain and arousal pathways to syndromal depression and anxiety. Molecular psychiatry 14, 681-695.

Gold, P.W., Chrousos, G.P., 2002. Organization of the stress system and its dysregulation in melancholic and atypical depression: high vs low CRH/NE states. Molecular psychiatry 7, 254-275. Golkar, A., Johansson, E., Kasahara, M., Osika, W., Perski, A., Savic, I., 2014. The influence of workrelated chronic stress on the regulation of emotion and on functional connectivity in the brain. PloS one 9, e104550.

Gonul, A.S., Akdeniz, F., Taneli, F., Donat, O., Eker, C., Vahip, S., 2005. Effect of treatment on serum brain-derived neurotrophic factor levels in depressed patients. European archives of psychiatry and clinical neuroscience 255, 381-386.

Gorman, J.M., Sloan, R.P., 2000. Heart rate variability in depressive and anxiety disorders. American heart journal 140, 77-83.

Gould, E., Beylin, A., Tanapat, P., Reeves, A., Shors, T.J., 1999. Learning enhances adult neurogenesis in the hippocampal formation. Nature neuroscience 2, 260-265.

Grassini, S., Nordin, S., 2015. Comorbidity in Migraine with Functional Somatic Syndromes, Psychiatric Disorders and Inflammatory Diseases: A Matter of Central Sensitization? Behavioral medicine (Washington, D.C.), 0.

Gruenewald, T.L., Seeman, T.E., Ryff, C.D., Karlamangla, A.S., Singer, B.H., 2006. Combinations of biomarkers predictive of later life mortality. Proceedings of the National Academy of Sciences of the United States of America 103, 14158-14163.

Gutierrez, B., Bellon, J.A., Rivera, M., Molina, E., King, M., Marston, L., Torres-Gonzalez, F., MorenoKustner, B., Moreno-Peral, P., Motrico, E., Monton-Franco, C., GildeGomez-Barragan, M.J., Sanchez- 
Celaya, M., Diaz-Barreiros, M.A., Vicens, C., de Dios Luna, J., Nazareth, I., Cervilla, J., 2015. The risk for major depression conferred by childhood maltreatment is multiplied by BDNF and SERT genetic vulnerability: a replication study. Journal of psychiatry \& neuroscience : JPN 40, 187-196.

Hayano, J., Sakakibara, Y., Yamada, A., Yamada, M., Mukai, S., Fujinami, T., Yokoyama, K., Watanabe, Y., Takata, K., 1991. Accuracy of assessment of cardiac vagal tone by heart rate variability in normal subjects. The American journal of cardiology 67, 199-204.

Heim, C., Newport, D.J., Heit, S., Graham, Y.P., Wilcox, M., Bonsall, R., Miller, A.H., Nemeroff, C.B., 2000. Pituitary-adrenal and autonomic responses to stress in women after sexual and physical abuse in childhood. JAMA : the journal of the American Medical Association 284, 592-597.

Hillert, A., Marwitz, M., 2008. Burnout: eine kritische Analyse mit therapeutischen Implikationen. Ärztliche Psychotherapie 4, 235-241.

Horsten, M., Ericson, M., Perski, A., Wamala, S.P., Schenck-Gustafsson, K., Orth-Gomer, K., 1999. Psychosocial factors and heart rate variability in healthy women. Psychosomatic medicine 61, 49-57. Jiang, R., Brummett, B.H., Babyak, M.A., Siegler, I.C., Williams, R.B., 2013. Brain-derived neurotrophic factor (BDNF) Val66Met and adulthood chronic stress interact to affect depressive symptoms. Journal of psychiatric research $47,233-239$.

Jiang, X., Xu, K., Hoberman, J., Tian, F., Marko, A.J., Waheed, J.F., Harris, C.R., Marini, A.M., Enoch, M.A., Lipsky, R.H., 2005. BDNF variation and mood disorders: a novel functional promoter polymorphism and Val66Met are associated with anxiety but have opposing effects.

Neuropsychopharmacology : official publication of the American College of

Neuropsychopharmacology 30, 1353-1361.

Joffe, R.T., Gatt, J.M., Kemp, A.H., Grieve, S., Dobson-Stone, C., Kuan, S.A., Schofield, P.R., Gordon, E., Williams, L.M., 2009. Brain derived neurotrophic factor Val66Met polymorphism, the five factor model of personality and hippocampal volume: Implications for depressive illness. Human brain mapping 30, 1246-1256.

Juhasz, G., Dunham, J.S., McKie, S., Thomas, E., Downey, D., Chase, D., Lloyd-Williams, K., Toth, Z.G., Platt, H., Mekli, K., Payton, A., Elliott, R., Williams, S.R., Anderson, I.M., Deakin, J.F., 2011. The CREB1BDNF-NTRK2 pathway in depression: multiple gene-cognition-environment interactions. Biological psychiatry 69, 762-771.

Juster, R.P., Sindi, S., Marin, M.F., Perna, A., Hashemi, A., Pruessner, J.C., Lupien, S.J., 2011. A clinical allostatic load index is associated with burnout symptoms and hypocortisolemic profiles in healthy workers. Psychoneuroendocrinology 36, 797-805.

Kageyama, T., Nishikido, N., Kobayashi, T., Kurokawa, Y., Kaneko, T., Kabuto, M., 1998. Self-reported sleep quality, job stress, and daytime autonomic activities assessed in terms of short-term heart rate variability among male white-collar workers. Industrial health 36, 263-272.

Kakiashvili, T., Leszek, J., Rutkowski, K., 2013. The medical perspective on burnout. International journal of occupational medicine and environmental health 26, 401-412.

Karege, F., Perret, G., Bondolfi, G., Schwald, M., Bertschy, G., Aubry, J.M., 2002. Decreased serum brain-derived neurotrophic factor levels in major depressed patients. Psychiatry research 109, 143148.

Kemp, A.H., Quintana, D.S., Felmingham, K.L., Matthews, S., Jelinek, H.F., 2012. Depression, comorbid anxiety disorders, and heart rate variability in physically healthy, unmedicated patients: implications for cardiovascular risk. PloS one 7, e30777.

Kendler, K.S., Gatz, M., Gardner, C.O., Pedersen, N.L., 2006. Personality and major depression: a Swedish longitudinal, population-based twin study. Archives of general psychiatry 63, 1113-1120. Kessler, R.C., 1997. The effects of stressful life events on depression. Annual review of psychology 48, 191-214.

Kessler, R.C., Berglund, P., Demler, O., Jin, R., Koretz, D., Merikangas, K.R., Rush, A.J., Walters, E.E., Wang, P.S., 2003. The epidemiology of major depressive disorder: results from the National Comorbidity Survey Replication (NCS-R). JAMA : the journal of the American Medical Association 289, 3095-3105. 
Koolschijn, P.C., van Haren, N.E., Lensvelt-Mulders, G.J., Hulshoff Pol, H.E., Kahn, R.S., 2009. Brain volume abnormalities in major depressive disorder: a meta-analysis of magnetic resonance imaging studies. Human brain mapping 30, 3719-3735.

Korte, M., Carroll, P., Wolf, E., Brem, G., Thoenen, H., Bonhoeffer, T., 1995. Hippocampal long-term potentiation is impaired in mice lacking brain-derived neurotrophic factor. Proceedings of the National Academy of Sciences of the United States of America 92, 8856-8860.

Korte, S.M., Koolhaas, J.M., Wingfield, J.C., McEwen, B.S., 2005. The Darwinian concept of stress: benefits of allostasis and costs of allostatic load and the trade-offs in health and disease.

Neuroscience and biobehavioral reviews 29, 3-38.

Kotov, A.V., Revina, N.E., 2012. Heart rate variability during "alarm stage" of burnout syndrome in emergency doctors. Bulletin of experimental biology and medicine 153, 598-600.

Lang, U.E., Hellweg, R., Kalus, P., Bajbouj, M., Lenzen, K.P., Sander, T., Kunz, D., Gallinat, J., 2005. Association of a functional BDNF polymorphism and anxiety-related personality traits.

Psychopharmacology 180, 95-99.

Lang, U.E., Hellweg, R., Seifert, F., Schubert, F., Gallinat, J., 2007. Correlation between serum brainderived neurotrophic factor level and an in vivo marker of cortical integrity. Biological psychiatry 62 , 530-535.

Lavebratt, C., Aberg, E., Sjoholm, L.K., Forsell, Y., 2010. Variations in FKBP5 and BDNF genes are suggestively associated with depression in a Swedish population-based cohort. Journal of affective disorders 125, 249-255.

Lennartsson, A.K., Jonsdottir, I., Sjors, A., 2016. Low heart rate variability in patients with clinical burnout. International journal of psychophysiology : official journal of the International Organization of Psychophysiology.

Licht, C.M., de Geus, E.J., Zitman, F.G., Hoogendijk, W.J., van Dyck, R., Penninx, B.W., 2008.

Association between major depressive disorder and heart rate variability in the Netherlands Study of Depression and Anxiety (NESDA). Archives of general psychiatry 65, 1358-1367.

Lipsky, R.H., Marini, A.M., 2007. Brain-derived neurotrophic factor in neuronal survival and behaviorrelated plasticity. Annals of the New York Academy of Sciences 1122, 130-143.

Loerbroks, A., Schilling, O., Haxsen, V., Jarczok, M.N., Thayer, J.F., Fischer, J.E., 2010. The fruits of ones labor: Effort-reward imbalance but not job strain is related to heart rate variability across the day in 35-44-year-old workers. Journal of psychosomatic research 69, 151-159.

Lu, B., 2003. BDNF and activity-dependent synaptic modulation. Learning \& memory (Cold Spring Harbor, N.Y.) 10, 86-98.

Lu, B., Gottschalk, W., 2000. Modulation of hippocampal synaptic transmission and plasticity by neurotrophins. Progress in brain research 128, 231-241.

Lupien, S.J., Evans, A., Lord, C., Miles, J., Pruessner, M., Pike, B., Pruessner, J.C., 2007. Hippocampal volume is as variable in young as in older adults: implications for the notion of hippocampal atrophy in humans. Neurolmage 34, 479-485.

Lupien, S.J., McEwen, B.S., Gunnar, M.R., Heim, C., 2009. Effects of stress throughout the lifespan on the brain, behaviour and cognition. Nature reviews. Neuroscience 10, 434-445.

MacQueen, G.M., Campbell, S., McEwen, B.S., Macdonald, K., Amano, S., Joffe, R.T., Nahmias, C., Young, L.T., 2003. Course of illness, hippocampal function, and hippocampal volume in major depression. Proceedings of the National Academy of Sciences of the United States of America 100, 1387-1392.

Madden, K., Savard, G.K., 1995. Effects of mental state on heart rate and blood pressure variability in men and women. Clinical physiology (Oxford, England) 15, 557-569.

Malter Cohen, M., Tottenham, N., Casey, B.J., 2013. Translational developmental studies of stress on brain and behavior: implications for adolescent mental health and illness? Neuroscience 249, 53-62.

Mandel, A.L., Ozdener, H., Utermohlen, V., 2011. Brain-derived neurotrophic factor in human saliva: ELISA optimization and biological correlates. Journal of immunoassay \& immunochemistry 32, 18-30. Maslach, C., Goldberg, J., 1998. Prevention of burnout: New perspectives. Applied \& Preventive Psychology 7, 63-74. 
Maslach, C., Schaufeli, W.B., Leiter, M.P., 2001. Job burnout. Annual review of psychology 52, 397422.

Mattson, M.P., Maudsley, S., Martin, B., 2004. BDNF and 5-HT: a dynamic duo in age-related neuronal plasticity and neurodegenerative disorders. Trends in neurosciences $27,589-594$.

Mauss, D., Li, J., Schmidt, B., Angerer, P., Jarczok, M.N., 2015. Measuring allostatic load in the workforce: a systematic review. Industrial health 53, 5-20.

McCraty, R., Atkinson, M., Tiller, W.A., Rein, G., Watkins, A.D., 1995. The effects of emotions on short-term power spectrum analysis of heart rate variability. The American journal of cardiology 76, 1089-1093.

McEwen, B.S., 1998. Protective and damaging effects of stress mediators. The New England journal of medicine 338, 171-179.

McEwen, B.S., Norton Lasley, E., 2002. The End of Stress as We Know it. Joseph Henry Press.

McEwen, B.S., Stellar, E., 1993. Stress and the individual. Mechanisms leading to disease. Archives of internal medicine 153, 2093-2101.

McHughen, S.A., Rodriguez, P.F., Kleim, J.A., Kleim, E.D., Marchal Crespo, L., Procaccio, V., Cramer, S.C., 2010. BDNF val66met polymorphism influences motor system function in the human brain.

Cerebral cortex (New York, N.Y. : 1991) 20, 1254-1262.

Meier, S., 1984. The construct validity of burnout. Journal of Occupationai Psychology 57, 211-219. Melamed, S., Shirom, A., Toker, S., Berliner, S., Shapira, I., 2006. Burnout and risk of cardiovascular disease: evidence, possible causal paths, and promising research directions. Psychological Bulletin 132, 327-353.

Milosevic, M., Jovanov, E., Frith, K.H., Vincent, J., Zaluzec, E., 2012. Preliminary analysis of physiological changes of nursing students during training. Conference proceedings : ... Annual International Conference of the IEEE Engineering in Medicine and Biology Society. IEEE Engineering in Medicine and Biology Society. Annual Conference 2012, 3772-3775.

Mitoma, M., Yoshimura, R., Sugita, A., Umene, W., Hori, H., Nakano, H., Ueda, N., Nakamura, J., 2008. Stress at work alters serum brain-derived neurotrophic factor (BDNF) levels and plasma 3-methoxy-4hydroxyphenylglycol (MHPG) levels in healthy volunteers: BDNF and MHPG as possible biological markers of mental stress? Progress in neuro-psychopharmacology \& biological psychiatry 32, 679685.

Miu, A.C., Heilman, R.M., Miclea, M., 2009. Reduced heart rate variability and vagal tone in anxiety: trait versus state, and the effects of autogenic training. Autonomic neuroscience : basic $\&$ clinical 145, 99-103.

Molendijk, M.L., van Tol, M.J., Penninx, B.W., van der Wee, N.J., Aleman, A., Veltman, D.J., Spinhoven, P., Elzinga, B.M., 2012. BDNF val66met affects hippocampal volume and emotion-related hippocampal memory activity. Translational psychiatry 2, e74.

Mommersteeg, P.M., Heijnen, C.J., Verbraak, M.J., van Doornen, L.J., 2006. Clinical burnout is not reflected in the cortisol awakening response, the day-curve or the response to a low-dose dexamethasone suppression test. Psychoneuroendocrinology 31, 216-225.

Montag, C., Weber, B., Fliessbach, K., Elger, C., Reuter, M., 2009. The BDNF Val66Met polymorphism impacts parahippocampal and amygdala volume in healthy humans: incremental support for a genetic risk factor for depression. Psychological medicine 39, 1831-1839.

Mujica-Parodi, L.R., Korgaonkar, M., Ravindranath, B., Greenberg, T., Tomasi, D., Wagshul, M., Ardekani, B., Guilfoyle, D., Khan, S., Zhong, Y., Chon, K., Malaspina, D., 2009. Limbic dysregulation is associated with lowered heart rate variability and increased trait anxiety in healthy adults. Human brain mapping $30,47-58$.

National Institute for Occupational Safety and Health (NIOSH), 1999. Stress at work. DHHS (NIOSH) Publication, Cincinnati, $\mathrm{OH}$.

Nemeroff, C.B., 2004. Neurobiological consequences of childhood trauma. The Journal of clinical psychiatry 65 Suppl 1, 18-28.

Nesse, R.M., 2000. Is depression an adaptation? Archives of general psychiatry 57, 14-20. 
Nolen-Hoeksema, S., 2000. The role of rumination in depressive disorders and mixed anxiety/depressive symptoms. J Abnorm Psychol 109, 504-511.

Nugent, N.R., Tyrka, A.R., Carpenter, L.L., Price, L.H., 2011. Gene-environment interactions: early life stress and risk for depressive and anxiety disorders. Psychopharmacology 214, 175-196.

Okuno, K., Yoshimura, R., Ueda, N., Ikenouchi-Sugita, A., Umene-Nakano, W., Hori, H., Hayashi, K., Katsuki, A., Chen, H.I., Nakamura, J., 2011. Relationships between stress, social adaptation, personality traits, brain-derived neurotrophic factor and 3-methoxy-4-hydroxyphenylglycol plasma concentrations in employees at a publishing company in Japan. Psychiatry research 186, 326-332. Onen Sertoz, O., Tolga Binbay, I., Koylu, E., Noyan, A., Yildirim, E., Elbi Mete, H., 2008. The role of BDNF and HPA axis in the neurobiology of burnout syndrome. Progress in neuropsychopharmacology \& biological psychiatry 32, 1459-1465.

Ottaviani, C., Shapiro, D., Davydov, D.M., Goldstein, I.B., Mills, P.J., 2009. The autonomic phenotype of rumination. International journal of psychophysiology : official journal of the International Organization of Psychophysiology 72, 267-275.

Pagani, M., Lombardi, F., Guzzetti, S., Rimoldi, O., Furlan, R., Pizzinelli, P., Sandrone, G., Malfatto, G., Dell'Orto, S., Piccaluga, E., et al., 1986. Power spectral analysis of heart rate and arterial pressure variabilities as a marker of sympatho-vagal interaction in man and conscious dog. Circulation research 59, 178-193.

Perea, C.S., Paternina, A.C., Gomez, Y., Lattig, M.C., 2012. Negative affectivity moderated by BDNF and stress response. Journal of affective disorders 136, 767-774.

Phelps, E.A., Delgado, M.R., Nearing, K.I., LeDoux, J.E., 2004. Extinction learning in humans: role of the amygdala and vmPFC. Neuron 43, 897-905.

Pieper, S., Brosschot, J.F., van der Leeden, R., Thayer, J.F., 2010. Prolonged cardiac effects of momentary assessed stressful events and worry episodes. Psychosomatic medicine 72, 570-577.

Pomeranz, B., Macaulay, R.J., Caudill, M.A., Kutz, I., Adam, D., Gordon, D., Kilborn, K.M., Barger, A.C., Shannon, D.C., Cohen, R.J., et al., 1985. Assessment of autonomic function in humans by heart rate spectral analysis. The American journal of physiology 248, H151-153.

Porges, S.W., 1995a. Cardiac vagal tone: a physiological index of stress. Neuroscience and biobehavioral reviews 19, 225-233.

Porges, S.W., 1995b. Orienting in a defensive world: mammalian modifications of our evolutionary heritage. A Polyvagal Theory. Psychophysiology 32, 301-318.

Quintana, D.S., Guastella, A.J., Outhred, T., Hickie, I.B., Kemp, A.H., 2012. Heart rate variability is associated with emotion recognition: direct evidence for a relationship between the autonomic nervous system and social cognition. International journal of psychophysiology : official journal of the International Organization of Psychophysiology 86, 168-172.

Radecki, D.T., Brown, L.M., Martinez, J., Teyler, T.J., 2005. BDNF protects against stress-induced impairments in spatial learning and memory and LTP. Hippocampus 15, 246-253.

Ressler, K.J., Nemeroff, C.B., 2000. Role of serotonergic and noradrenergic systems in the pathophysiology of depression and anxiety disorders. Depression and anxiety 12 Suppl 1, 2-19. Reyes del Paso, G.A., Langewitz, W., Mulder, L.J., van Roon, A., Duschek, S., 2013. The utility of low frequency heart rate variability as an index of sympathetic cardiac tone: a review with emphasis on a reanalysis of previous studies. Psychophysiology 50, 477-487.

Sapolsky, R.M., 2000a. Glucocorticoids and hippocampal atrophy in neuropsychiatric disorders. Archives of general psychiatry 57, 925-935.

Sapolsky, R.M., 2000b. The possibility of neurotoxicity in the hippocampus in major depression: a primer on neuron death. Biological psychiatry 48, 755-765.

Sartorius, A., Hellweg, R., Litzke, J., Vogt, M., Dormann, C., Vollmayr, B., Danker-Hopfe, H., Gass, P., 2009. Correlations and discrepancies between serum and brain tissue levels of neurotrophins after electroconvulsive treatment in rats. Pharmacopsychiatry 42, 270-276.

Savic, I., 2015. Structural changes of the brain in relation to occupational stress. Cerebral cortex 25, 1554-1564.

Schonfeld, I.S., Bianchi, R., 2015. Burnout and Depression: Two Entities or One? J Clin Psychol. 
Schule, C., Zill, P., Baghai, T.C., Eser, D., Zwanzger, P., Wenig, N., Rupprecht, R., Bondy, B., 2006. Brain-derived neurotrophic factor Val66Met polymorphism and dexamethasone/CRH test results in depressed patients. Psychoneuroendocrinology 31, 1019-1025.

Schwerdtfeger, A., Friedrich-Mai, P., 2009. Social interaction moderates the relationship between depressive mood and heart rate variability: evidence from an ambulatory monitoring study. Health psychology : official journal of the Division of Health Psychology, American Psychological Association 28, 501-509.

Seeman, T.E., Singer, B.H., Rowe, J.W., Horwitz, R.I., McEwen, B.S., 1997. Price of adaptation-allostatic load and its health consequences. MacArthur studies of successful aging. Archives of internal medicine 157, 2259-2268.

Sen, S., Duman, R., Sanacora, G., 2008. Serum brain-derived neurotrophic factor, depression, and antidepressant medications: meta-analyses and implications. Biological psychiatry 64, 527-532. Sen, S., Nesse, R.M., Stoltenberg, S.F., Li, S., Gleiberman, L., Chakravarti, A., Weder, A.B., Burmeister, $M ., 2003$. A BDNF coding variant is associated with the NEO personality inventory domain neuroticism, a risk factor for depression. Neuropsychopharmacology : official publication of the American College of Neuropsychopharmacology 28, 397-401.

Shalev, I., Lerer, E., Israel, S., Uzefovsky, F., Gritsenko, I., Mankuta, D., Ebstein, R.P., Kaitz, M., 2009. BDNF Val66Met polymorphism is associated with HPA axis reactivity to psychological stress characterized by genotype and gender interactions. Psychoneuroendocrinology 34, 382-388. Shimizu, E., Hashimoto, K., Okamura, N., Koike, K., Komatsu, N., Kumakiri, C., Nakazato, M., Watanabe, H., Shinoda, N., Okada, S., lyo, M., 2003. Alterations of serum levels of brain-derived neurotrophic factor (BDNF) in depressed patients with or without antidepressants. Biological psychiatry 54, 70-75.

Shinba, T., Kariya, N., Matsui, Y., Ozawa, N., Matsuda, Y., Yamamoto, K., 2008. Decrease in heart rate variability response to task is related to anxiety and depressiveness in normal subjects. Psychiatry and clinical neurosciences 62, 603-609.

Sjoholm, L., Lavebratt, C., Forsell, Y., 2009. A multifactorial developmental model for the etiology of major depression in a population-based sample. Journal of affective disorders 113, 66-76.

Soliman, F., Glatt, C.E., Bath, K.G., Levita, L., Jones, R.M., Pattwell, S.S., Jing, D., Tottenham, N., Amso, D., Somerville, L.H., Voss, H.U., Glover, G., Ballon, D.J., Liston, C., Teslovich, T., Van Kempen, T., Lee, F.S., Casey, B.J., 2010. A genetic variant BDNF polymorphism alters extinction learning in both mouse and human. Science (New York, N.Y.) 327, 863-866.

Sullivan, P.F., Neale, M.C., Kendler, K.S., 2000. Genetic epidemiology of major depression: review and meta-analysis. The American journal of psychiatry 157, 1552-1562.

Swaab, D.F., Bao, A.M., Lucassen, P.J., 2005. The stress system in the human brain in depression and neurodegeneration. Ageing research reviews 4, 141-194.

Task Force of the European Society of Cardiology and the North American Society of Pacing and Electrophysiology, 1996. Heart rate variability. Standards of measurement, physiological interpretation, and clinical use. . European heart journal 17, 354-381.

Taylor, C.B., 2010. Depression, heart rate related variables and cardiovascular disease. International journal of psychophysiology : official journal of the International Organization of Psychophysiology 78, 80-88.

Tement, S., Pahor, A., Jausovec, N., 2015. EEG alpha frequency correlates of burnout and depression: The role of gender. Biological psychology.

Tennant, C., 2002. Life events, stress and depression: a review of recent findings. The Australian and New Zealand journal of psychiatry 36, 173-182.

Terracciano, A., Martin, B., Ansari, D., Tanaka, T., Ferrucci, L., Maudsley, S., Mattson, M.P., Costa, P.T., Jr., 2010. Plasma BDNF concentration, Val66Met genetic variant and depression-related personality traits. Genes, brain, and behavior 9, 512-518.

Thayer, J.F., Hansen, A.L., Saus-Rose, E., Johnsen, B.H., 2009. Heart rate variability, prefrontal neural function, and cognitive performance: the neurovisceral integration perspective on self-regulation, 
adaptation, and health. Annals of behavioral medicine : a publication of the Society of Behavioral Medicine 37, 141-153.

Tulen, J.H., Bruijn, J.A., de Man, K.J., van der Velden, E., Pepplinkhuizen, L., Man in 't Veld, A.J., 1996. Anxiety and autonomic regulation in major depressive disorder: an exploratory study. Journal of affective disorders 40, 61-71.

von Kanel, R., 2008. [The burnout syndrome: a medical perspective]. Praxis 97, 477-487.

Vythilingam, M., Heim, C., Newport, J., Miller, A.H., Anderson, E., Bronen, R., Brummer, M., Staib, L., Vermetten, E., Charney, D.S., Nemeroff, C.B., Bremner, J.D., 2002. Childhood trauma associated with smaller hippocampal volume in women with major depression. The American journal of psychiatry 159, 2072-2080.

Waterhouse, E.G., Xu, B., 2009. New insights into the role of brain-derived neurotrophic factor in synaptic plasticity. Molecular and cellular neurosciences 42, 81-89.

Weiskopf, P.E., 1980. Burnout among teachers of exceptional children. Exceptional children 47, 1823.

Weissman, M.M., Bland, R.C., Canino, G.J., Faravelli, C., Greenwald, S., Hwu, H.G., Joyce, P.R., Karam, E.G., Lee, C.K., Lellouch, J., Lepine, J.P., Newman, S.C., Rubio-Stipec, M., Wells, J.E., Wickramaratne, P.J., Wittchen, H., Yeh, E.K., 1996. Cross-national epidemiology of major depression and bipolar disorder. JAMA : the journal of the American Medical Association 276, 293-299.

World Health Organisation, October 2015. Fact sheet $\mathrm{N}^{\circ} 369$.

Yamasue, H., Abe, O., Suga, M., Yamada, H., Inoue, H., Tochigi, M., Rogers, M., Aoki, S., Kato, N., Kasai, K., 2008. Gender-common and -specific neuroanatomical basis of human anxiety-related personality traits. Cerebral cortex (New York, N.Y. : 1991) 18, 46-52.

Yang, A.C., Chen, T.J., Tsai, S.J., Hong, C.J., Kuo, C.H., Yang, C.H., Kao, K.P., 2010. BDNF Val66Met polymorphism alters sympathovagal balance in healthy subjects. American journal of medical genetics. Part B, Neuropsychiatric genetics : the official publication of the International Society of Psychiatric Genetics 153B, 1024-1030.

Yeragani, V.K., Pohl, R., Balon, R., Ramesh, C., Glitz, D., Jung, I., Sherwood, P., 1991. Heart rate variability in patients with major depression. Psychiatry research 37, 35-46.

Yeragani, V.K., Pohl, R., Berger, R., Balon, R., Ramesh, C., Glitz, D., Srinivasan, K., Weinberg, P., 1993. Decreased heart rate variability in panic disorder patients: a study of power-spectral analysis of heart rate. Psychiatry research 46, 89-103.

Zannas, A.S., McQuoid, D.R., Payne, M.E., Steffens, D.C., MacFall, J.R., Ashley-Koch, A., Taylor, W.D., 2013. Negative life stress and longitudinal hippocampal volume changes in older adults with and without depression. Journal of psychiatric research 47, 829-834.

Zanstra, Y.J., Schellekens, J.M., Schaap, C., Kooistra, L., 2006. Vagal and sympathetic activity in burnouts during a mentally demanding workday. Psychosomatic medicine 68, 583-590. 